\title{
La ciudad creativa y cultural como espacio de exclusión y segregación. Analizando La Placica Vintage de Zaragoza: materialidades, prácticas, narrativas y virtualidades
}

Jorge Sánchez-Naudin. Universitat Oberta de Catalunya, Barcelona, España. Pep Vivas-Elias. Universitat Oberta de Catalunya, Barcelona, Espańa.

RESUMEN | La ciudad creativa y cultural emerge como paradigma de gestión económica y socioterritorial en las urbes contemporáneas. Zaragoza no es ajena a ello, con la realización de proyectos de regeneración urbana a través de acciones urbanísticas estructurales (Plan Especial de Reforma Interior [PERI]) y la producción de actividades efímeras en zonas concretas de la ciudad (La Placica Vintage). Este caso de estudio explora cómo se compone, de una manera articulada, un espacio de la ciudad en el que convergen ambos tipos de actuaciones -acciones urbanísticas estructurales y producción de actividades efímeras- a través de cuatro ejes principales: materialidad; prácticas performativas; narrativas y discursos y virtualidad. Para ello utilizamos las posibilidades etnográficas que el lugar-ensamblaje posibilita en el análisis de espacios emergentes y efímeros, problematizando el propio lugar de trabajo y multisituando dicho análisis. Finalizaremos destacando los procesos de segregación y exclusión social que se producen en la zona estudiada, contribuyendo con ello al debate público sobre los procesos de gentrificación que tienen lugar en nuestras ciudades.

PALABRAS ClAVE | centros urbanos, gentrificación, segregación.

ABSTRACT | The creative and cultural city emerges as a paradigm of economic and socio-territorial management in contemporary cities. Zaragoza is no stranger to this issue, carrying out urban regeneration projects through structural urban actions (Plan Especial de Reforma Interior [PERI]/Special Plan for Internal Reform) and the production of ephemeral activities in specific areas of the city (La Placica Vintage). This case study explores how a determined space of the city is composed in an articulate manner-and in which both types of actions converge through four main axes: Materiality, performative practices, narratives and discourses, and virtuality. For this, we use the ethnographic possibilities that the place-assemblage allows in the analysis of emerging and ephemeral spaces, problematizing the workplace itself and multiplying this analysis. We then highlight the processes of segregation and social exclusion that occur in the studied area, thus contributing to the public debate on gentrification processes that occur in our cities.

KEYWORDS | urban centers, gentrification, segregation. 


\section{Introducción}

A lo largo de estas últimas décadas, la transformación de las ciudades, por su crecimiento físico y por la magnitud de concentración de personas en lugares puntuales del planeta, ha sido colosal. El mundo, tal y como lo conocemos y lo habitamos, es hoy urbano. Aunque existan aún rincones del planeta sin habitar o sin construcción, afirmamos que es urbano dado que las ciudades están estrechamente ligadas al modelo socioeconómico poscapitalista. A su vez, las urbes han posibilitado que las tecnologías se anclen y se difuminen por el aire de las ciudades, por el interior de casas y de edificios públicos y privados, por el subsuelo de las mismas. Esta nueva capa tecnológica (que va más allá de la estructura física y material, y de su estructura humana y social) ha fomentado todavía más la interconexión y el intercambio económico y de los mercados, el control social por parte de las instituciones de poder y la interrelación de las personas que viven en la misma ciudad o con otras que viven en cualquier sitio del planeta. En la actualidad las ciudades no solo están construidas por calles, edificios, etcétera, ni por las personas que las habitan, que las pasean, etcétera. El componente tecnológico es esencial para entender y mirar las ciudades, dado que la tecnología se imbrica directamente con la materialidad urbana y el espacio público, e influye en la relación entre las personas y de estas con la ciudad.

De la misma manera que las ciudades siguen creciendo, transformándose y adaptándose al mercado, y la realidad poscapitalista ejerce de terreno y de territorio imprescindible para que se reproduzcan, las urbes siguen innovando y reinventando productos que sean útiles y vendibles en el feroz espacio global. De hecho, las ciudades se han convertido en un producto más de mercado en cuanto al valor y a la competitividad. En la actualidad, su reinvención y actualización pasa por generar, entre otros, ciertas atmósferas e imaginarios creativos y culturales que pretenden componer espacios cool: una ciudad a la última que innova y se reinventa de manera constante. Esta fashionización y snobización urbana pasa por recuperar y resignificar productos y prácticas, reinsertándolos dentro del modelo global. Hacer ciudad, por tanto, a través de la realización de eventos efímeros y fugaces, se relaciona con procesos de exclusión, segregación y gentrificación urbana, como pondremos de manifiesto a lo largo de este artículo.

Zaragoza es una ciudad que no se escapa de este proceso. Mediante ciertas políticas urbanas y económicas, y a través de ciertas intervenciones culturales y creativas -como nuestro estudio de caso de La Placica Vintage, donde convergen lo global y lo local-, emergen procesos de exclusión y segregación urbana en la zona del centro histórico de la ciudad que van más allá de la intervención urbanística y económica. Es decir, tienen como finalidad la revalorización del espacio a nivel económico, cultural y social.

\section{La ciudad creativa y cultural: breve recorrido teórico y crítico}

Para una comprensión de la ciudad creativa hemos de tener presente que sus principios descansan sobre la economía creativa. Actualmente, el centro de dicha economía lo componen sectores cuya actividad se focaliza en la producción, promoción, 
difusión y comercialización de bienes, servicios y actividades de contenido cultural, artístico o patrimonial.

El concepto "economía creativa' no es nuevo. Surgido a finales del siglo pasado y consolidado a lo largo de estos años, sus raíces se remontan al fenómeno de las industrias culturales, y emergió como tal a partir del término "industrias creativas". El surgimiento de estas industrias se entiende en un contexto de cambio en los modelos de producción de la ciudad posindustrial: de un sistema socioeconómico fordista basado en la producción industrial, a su conversión en una economía posfordista en la que recursos como la información, la comunicación o la creatividad se convierten en potencias valorizantes del trabajo. Esta economía basada en la generación de ideas, conocimiento e innovación ha sido denominada como "capitalismo cognitivo" (Fumagalli, 2010).

A lo largo de la literatura sobre la "ciudad creativa" existe un cierto consenso en señalar el origen de este concepto en el economista sueco Anderson (1985), quien ya puso de manifiesto la importancia de la creatividad en las economías emergentes posindustriales. No obstante, son constantes las referencias a la activista urbana Jacobs $(1961,1969)$, considerada un antecedente por su formulación de ideas transformadoras en el ámbito de la planificación urbana y el activismo comunitario. Una década después de la aparición de la publicación de Anderson, los autores Landry y Bianchini (1995) relacionan la creatividad con el desarrollo económico y la participación. Con tal fin, exploran cómo la creatividad puede ser utilizada para mejorar la vida en las ciudades, la necesidad que tiene la planificación urbana de enfoques multidisciplinares y de experiencias participativas, y cómo la creatividad puede ser puesta en práctica a través del desarrollo de entornos creativos. Cinco ańos después, Landry (2000), retomando los postulados de Landry y Bianchini sobre la ciudad creativa, establece un diálogo práctico con los problemas y transformaciones urbanas a través de soluciones creativas.

Algo más tarde, a partir de la obra de Richard Florida sobre la "clase creativa" y cómo está transformando el trabajo, el ocio la comunidad y la vida diaria (2002), el impacto que se produjo en la cuestión de la ciudad creativa se expandió a un ritmo vertiginoso por distintos lugares en el mundo, abarcando el ámbito del planeamiento urbano y de las políticas y economías regionales. En ese libro, el autor describe las características de las personas creativas en las ciudades y cómo su quehacer incide en los valores sociales, la gestión del tiempo libre, la estructura familiar y el estilo de vida. Fundamentalmente, su tesis radica en que la creatividad, como valor del trabajo, va a alcanzar una posición privilegiada en unas economías en transformación como las actuales, cuyo cambio "se basa fundamentalmente en la inteligencia, el conocimiento y la creatividad humana” (Florida, 2002, p. 11). Así, señala, la competitividad económica de una ciudad emerge a través de su "capacidad de atraer y mantener a las personas creativas" (p. 19), lo que apunta a la importancia que otorga Florida a los aspectos sociales de la creatividad: ambientes laborales y urbanos flexibles y un ecosistema tolerante, multicultural, sin barreras étnicas, de raza, orientación sexual o nacionalidad; esto es, inclusivo y tolerante. En una publicación posterior, Florida (2009) ahonda en la importancia de la creatividad para la economía, la cohesión, la cultura y la ciudad. 
La producción literaria en torno a la ciudad creativa ha generado diversas tensiones teóricas, especialmente relacionadas con las tesis de Florida, que han propiciado los debates más acalorados. Peck (2005) desarrolla una crítica de los conceptos "clase creativa" y "ciudades creativas", remarcando un énfasis elitista y poniendo en duda ciertos datos. Este autor considera que el alcance político-geográfico de estos discursos se explica en función de los contextos urbanos profundamente neoliberalizados en los que se despliegan, más que por sus méritos intrínsecos: las estrategias creativas basadas en la innovación cultural liberal apenas afectan las dinámicas de las políticas urbanas existentes (competencia interlocal, procesos de gentrificación, marketing urbano o desigualdad socioespacial normalizada), sino que extienden y recodifican inercias afianzadas en políticas urbanas neoliberales, elevando la creatividad a un nuevo imperativo urbano.

La cuestión de la atractividad local también ha sido puesta en duda por algunos autores. Nichols (2003) cuestiona que determinadas amenities, como cafés y bares modernos, restaurantes trendy, librerías de segunda mano o ambientes bohemios, conduzcan a elegir esas localizaciones para vivir. En esta misma línea, otros autores cuestionan que sea una "clase" la que genera el desarrollo económico de una ciudad, sino que este se debe al complejo aparato del sistema de producción urbano y no a la migración unilateral e interna de tipos de trabajadores particulares (Scott, 2007). Señalan que este tipo de proposiciones, que solo tienen en cuenta un porcentaje de la población categorizada como clase creativa y privilegiada de talento creativo, van dirigidas exclusivamente a una reducida elite con un determinado poder adquisitivo. En este sentido, la capacidad de elegir dónde vivir (Florida, 2009) sería otro ejemplo de postulado que destila elitismo creativo (Shearmur, 2006), y que oculta o deja a un lado la complejidad de las dinámicas urbanas y los procesos de exclusión y desigualdad social. Así, esta ciudad creativa no parece interesarse por los desafíos de la escala de barrio y la vida cotidiana, ni por las desigualdades propias de la nueva economía, saltando por encima de los conflictos que surgen de las definiciones simplificadas de cultura, patrimonio y creatividad (Sabaté \& Tironi, 2008).

Desde otra línea de pensamiento, se subraya que las actividades, bienes y servicios que surgen de la economía creativa aterrizan en las zonas urbanas de las ciudades a través de diferentes representaciones (Unctad, 2008; 2010). Por un lado, a través de la pintura, literatura, cine, fotografía, música o el diseño (arquitectura, planificación urbana, gráfico o editorial). También mediante la presencia del patrimonio cultural y la arquitectura. $\mathrm{O}$, por último, a través de actividades culturales en espacios urbanos específicos, como eventos, festivales, exposiciones o conciertos. La cultura, por tanto, a través de las industrias culturales y creativas, tiene en la ciudad un marco privilegiado para sus actividades. Las ciudades han incorporado el sector cultural y creativo como motor de su desarrollo y crecimiento económico. No obstante, los discursos en torno a la cultura transcienden su consideración como un mero motor económico (porcentaje del PIB, creador de empleo o factor de competitividad y marketing urbano) y generador de servicios culturales básicos, para articular narrativas en torno al desarrollo sostenible, la inclusión social, la regeneración urbana o la mejora de la calidad de vida. 
Ciudades en las que se han llevado a cabo procesos de revitalización a través de la cultura son París (Montmartre y Monrparnasse), Argentina (La Boca) o Nueva York (Soho), como ejemplos paradigmáticos de procesos de revitalización urbana o gentrificación sin la intervención de políticas urbanas. En el otro extremo encontraríamos proyectos de revitalización a través de la instalación de centros o nuevas instituciones culturales, que fomentan la implantación de negocios de restauración o pequeños negocios culturales y creativos (galerías de arte, librerías específicas o estudios de diseño gráfico y arquitectura). Ciudades como Manchester (Lorry Centre, en Salford), Birmingham (The New Art Gallery, en Walsall), Medellín a través de los Parque Biblioteca, Londres y el Tate Modern o Bilbao y el Guggenheim son ejemplos de un cambio de lógica en las políticas de regeneración urbana con el fin de revitalizar económicamente las ciudades posindustriales. A través de estas transformaciones, ciudades de todo el mundo han construido modelos y políticas de desarrollo y regeneración urbana basados en las industrias turísticas, culturales y creativas, entendiendo que estrategias de este tipo comportan beneficios tanto económicos (creación de puestos de trabajo o desarrollo de las industrias del ocio) como sociales (revitalización del espacio público, educación o participación ciudadana) (Cassian, 2012).

De una manera contestataria, la relación entre ciudad y las industrias culturales y creativas ha sido analizada de manera crítica, señalándose cuestiones como las consecuencias que se derivan de orientar las ciudades hacia el turismo (Urry, 1990, 2008) o la simplificación de la ciudad a una "marca", que esconde nuevas formas culturales y definiciones de autenticidad y originalidad, con el fin de promocionarla y rentabilizarla a través de los flujos de capital de carácter internacional (Harvey, 1985). Adicionalmente, la geografía urbana de tradición marxista definió estos distritos creativos como enclaves gentrificados propios de los procesos de acumulación capitalista (Deutsche \& Ryan, 1984; Melé, 2003; Podmore, 1998; Shaw, 2002; Smith, 2002; Zukin, 1989). Así pues, señala Sequera (2017), este tipo de intervenciones se relaciona directamente con cierto orden de dinámicas "de fragmentación de la ciudadanía, de individualización y de globalización y, por supuesto, con nuevos estilos de vida y consumo distintivos que se reflejan en la manera de entender la ciudad, que también se ve fragmentada y segregada socialmente por las distintas identidades" (p. 2) y figuras emergentes. Se trata de atraer hacia estos renovados centros urbanos a la denominada "clase creativa”, continúa el autor (p. 2) (artistas, diseñadores, intelectuales, actores, etcétera), con la premisa de que las zonas urbanas más desarrolladas económica y socialmente serán aquellas que sepan potenciar ciertos estilos de vida alternativos que guarden relación con la creatividad y el consumo. Para el mismo Sequera, las políticas urbanas que se fundamentan en esta premisa promueven "procesos de gentrificación en torno a la noción de clase creativa (Boschma \& Fritsch, 2009; Krätke, 2010; Lang \& Danielsen, 2005; Markusen, 2006; Peck, 2005; Scott 2004, 2006) y son el correlato de un sistema de prácticas que condicionan el espacio social y sus usos" (p. 2). En consecuencia, agrega, se generan ciertos tipos de prácticas sociales características de esta "clase creativa" que se yuxtaponen a otras prácticas sociales que suceden o se producían en estos espacios. Con ello lo que se está provocando es un "desplazamiento directo o 
indirecto (Marcuse, 1985; Slater, 2009) de una población no deseada sobre el lugar a revalorizar" (p. 2).

En definitiva, cuando se produce un proceso de gentrificación, cuando se observan fenómenos de exclusión o segregación urbana, social y económica, hay que tener en consideración diferentes aspectos que ya han sido analizados, desde hace décadas, por diferentes autores. En primer lugar, la cuestión arquitectónica y física de la gentrificación: cómo se transforma un espacio mediante una serie de intervenciones dirigidas tanto a la rehabilitación como a la construcción de nuevos edificios (Glass, 1964), que afecta a barrios populares generalmente en el centro de la ciudad. Segundo, el cambio de la ocupación social del espacio (Castells, 1995) que, en la mejora de la vivienda, acentúa procesos como la segregación residencial. Tercero, cómo se vinculan los procesos de regeneración urbana con los usos recreativos y comerciales (Smith \& Williams, 1986), y cómo estos se relacionan con los efectos de la organización productiva del espacio (Ley, 1986, 1987; Smith, 1987). Finalmente $-\mathrm{y}$ el caso que a continuación presentaremos es un claro ejemplo de ello-, cómo el fenómeno de gentrificación se relaciona con las oportunidades de consumo, el estilo de vida o la actitud pionera (hoy podría leerse emprendedora y creativa) de las clases medias, en las que se produce una interacción clara entre la dimensión cultural y los factores económicos (Zukin, 1998).

\section{Plan Especial de Reforma Interior (PERI) Armas-Casta Álvarez: una intervención urbanística, creativa y cultural}

El espacio objeto de nuestro análisis está delimitado por las calles Casta Álvarez, Aguadores, Armas y Sacramento, del barrio del Gancho, que pertenece al distrito del Casco Histórico de la ciudad de Zaragoza. El escenario que se analiza es conocido popularmente como Las Armas. Este espacio ha sido objeto de un proyecto de transformación conocido como el Plan Especial de Reforma Interior (PERI) ArmasCasta Álvarez. Este proyecto pertenece a un proceso de regeneración urbana que comenzó en el año 1997, cuando se puso en marcha el Plan Integral del Casco Histórico (PICH). ${ }^{1}$ En lo sucesivo, se han ido aprobando planes plurianuales que continúan, retoman y definen nuevas necesidades de actuación para el conjunto del Casco Histórico de la ciudad. Concretamente, y a nivel urbanístico y arquitectónico, se han llevado a cabo las siguientes actuaciones (figura 1): la construcción de una plaza pública entre las calles Armas y Sacramento; la construcción de un equipamiento público que sirva de elemento de atracción urbana en el frente de la plaza; la construcción de edificios residenciales con ochenta y dos viviendas de protección oficial, trasteros, garajes y locales; la creación de un espacio interior de manzana privado de uso público conectado a las calles y plaza circundantes; la adecuación de once locales comerciales para el emprendedor creativo construidos en las edificaciones residenciales con el fin de actuar sobre el tejido comercial de la zona; y un centro musical. 
Adicionalmente, y en torno al lugar que nos ocupa, también se han llevado a cabo diversas actuaciones que reconfiguran las posibilidades socioterritoriales y sociomateriales del espacio: la recuperación del solar del circo social, la regeneración de uno de los solares a través del proyecto \#estonoesunsolar ${ }^{2}$ y la intervención de buena parte de las fachadas del entorno a través del proyecto Festival Asalto. ${ }^{3}$

\section{FIGURA I | Intervención urbanística PERI}

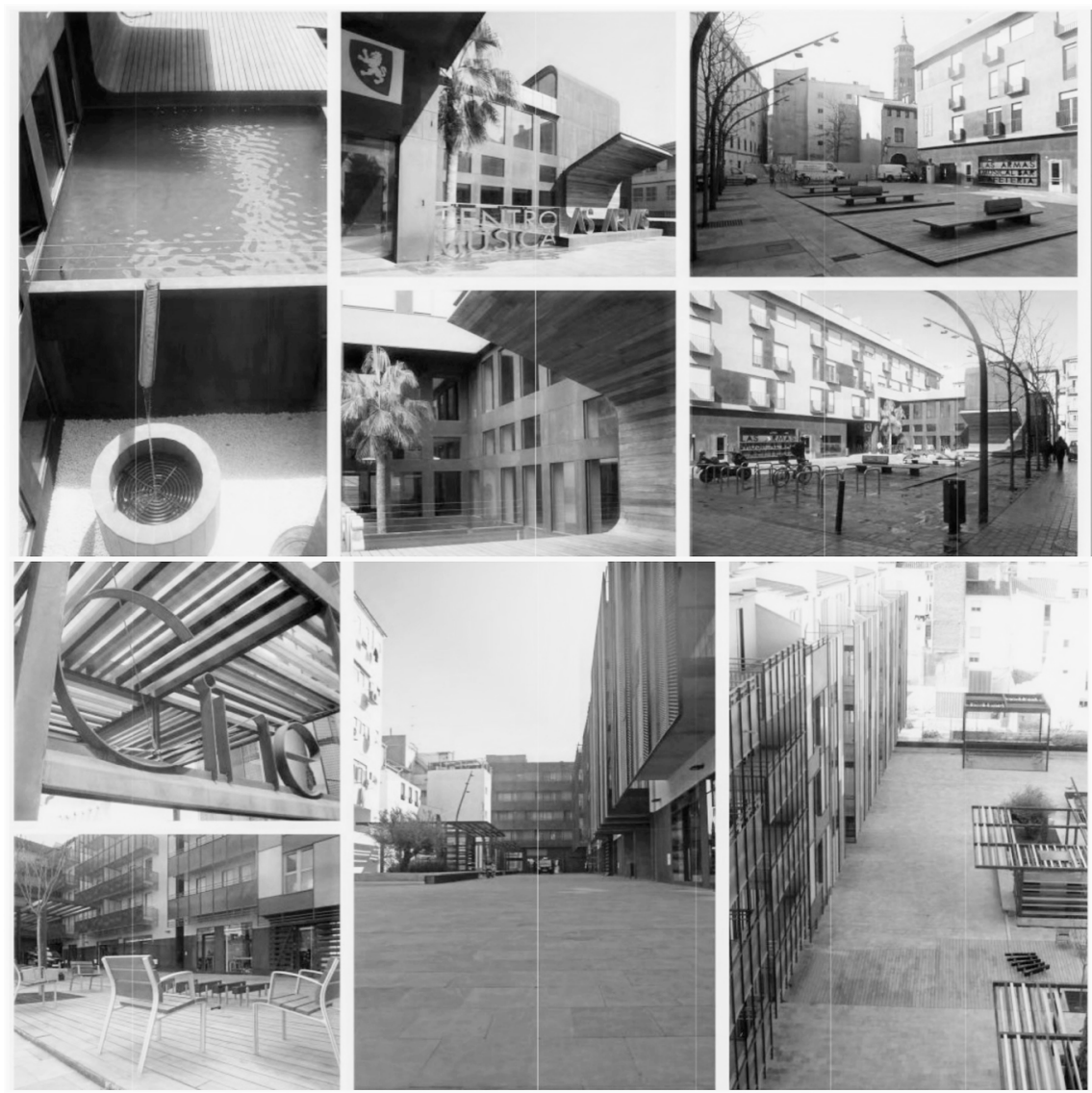

NOTA

EN LAS IMÁGENES SE PUEDE APRECIAR LA DISPOSICIÓN DEL OBJETO DE ESTUDIO CON SU PLAZA DE NUEVA CREACIÓN, LAS VIVIENDAS DE PROTECCIÓN OFICIAL, EL CENTRO MUSICAL Y LOS LOCALES CREATIVOS (EN LOS BAJOS DE LAS VIVIENDAS) COMO EJEMPLOS DE LA NUEVA PRODUCCIÓN ECONÓMICA CULTURAL.

FUENTE ZARAGOZA VIVIENDA (2OI2), ACTUACIÓN URBANÍSTICA EN EL PERI ARMAS-CASTA ÁLVAREZ. PREMIOS 3 DE ABRIL, OCTAVA EDICIÓN, URBANISMO Y ARQUITECTURA. HTTP://BIT.LY/2CZZCYA

2 Archivo para la categoría "San Pablo". "Emplazamientos de los 28 solares recuperados con el programa estonoesunsolar", 31/12/2013. https://estonoesunsolar.wordpress.com/category/sanpablo/

3 Festival Asalto, Festival Internacional de Arte Urbano. http://www.festivalasalto.com/ 
Nos encontramos, por tanto, ante una forma de regeneración urbana a través de las industrias creativas y culturales en un espacio situado en el distrito del Casco Histórico de Zaragoza, que se encuentra en un proceso de transformación en lugar de entretenimiento, ocio y locales de emprendedores creativos donde adquirir productos determinados. Lo que parece claro es que estas estrategias de regeneración tienen en común la creencia en un proceso de globalización que está íntimamente ligado a un cambio desde la producción industrial a la producción cultural o informacional. Esta forma de desarrollo urbano depende fuertemente de políticas relacionadas con el posfordismo; la sociedad red y de la información; la globalización y la movilidad (Slater \& Aritztia, 2009).

\section{Recorrido etnográfico y tensiones metodológicas}

El proceso de trabajo de campo, llevado a cabo desde el año 2014 hasta enero de 2017 (decimocuarta edición de La Placica Vintage), ha consistido en la recopilación de una gran cantidad de datos empíricos en formatos de diferentes características: fotografías propias o de otros autores; textos publicados en webs, blogs y otras redes sociales; la propia observación y participación en los eventos; conversaciones y entrevistas con participantes, usuarios y/o promotores; exploración de fragmentos de textos y entrevistas realizadas por otros medios; visualización y análisis de vídeos, entre otros. Dada la gran cantidad de datos recopilados y al ser tan variados en cuanto a sus características, surgieron tensiones metodológicas que han ido reconfigurando el propio proceso etnográfico y que nos ayudaron a trazar diversos ejes (materialidad; prácticas sociales performativas; narrativas y discursos; y virtualidad) para el análisis del ejemplo de intervención seleccionado.

En primer lugar, la captura y la recopilación de las escenas e instantáneas colectivas y urbanas resulta una de las tareas más complejas para el investigador social. En este sentido, considerábamos necesaria la utilización de variadas técnicas que captasen elementos complejos y diferentes íntimamente interconectados, lo que implicaba recoger y analizar fragmentos de realidades urbanas conectadas que pueden tener características diferentes. Se trataba no solo de elementos materiales o estructurales que responden a la intervención urbanística y que moldean el paisaje urbano específico (locales de emprendedores creativos, el centro musical, el escenario de conciertos o las intervenciones artísticas en las fachadas de los edificios contiguos), sino también elementos materiales con un carácter nómada, como los distintos objetos y productos vintage que se venden en el espacio, elementos visuales o sonidos musicales, o las propias tiendas efímeras. Por otro lado, era necesario incorporar las propias prácticas de ocio y consumo que se llevan a cabo y las narrativas y los discursos que subyacen a las interacciones, conversaciones cotidianas y en las entrevistas que realizamos.

Con este entramado de datos etnográficos de diferentes características optamos, en primer lugar, por usar el concepto de "lugar-ensamblaje" (Di Masso \& Dixon, 2015) como unidad de análisis y, a su vez, como concepto metodológico. Es decir, podemos desentrañar la conexión e interdependencia de los ejemplos aislados recopilados de discursos, espacios, materialidades, virtualidades o corporeidades. Así, el "lugar-ensamblaje" toma forma ontológica para convertirse en una "porción" de la 
realidad que puede analizarse, dependiendo del contexto y de las prácticas sociales y textuales que lo rodean. A su vez, el "lugar-ensamblaje" como constructor de la ciudad posibilita observar y analizar las ciudades desde su multiplicidad. Siguiendo a Farías (2011), "los ensamblajes emergen al involucrar conjuntos de relaciones que, si bien dependen de ellas, se actualizan a través de la interacción con otras entidades produciendo la ciudad, encontrándose entrelazados y articulados a través de múltiples niveles y redes que hacen proliferar capacidades de acción de la ciudad" (p. 58). Así pues, dicho concepto ofrece una base sólida para comprender las ciudades del presente como entidades que conectan espacios concretos de la práctica urbana, una combinación de devenires urbanos acoplados a redes sociales y tecnológicas; a colectivos híbridos; y topologías y prácticas urbanas siempre mutables. Si tomamos este concepto como unidad de análisis, la ciudad debe comprenderse como un objeto múltiple, complejo y sin centros, sin posibilidad de acotación ni de perfilar sus límites, y sin contextos específicos y únicos para su construcción: lo efímero, lo líquido, lo fugaz, lo dinámico, etcétera, conforma lo urbano en todos sus sentidos y aspectos.

En segundo lugar, consideramos que la ciudad está siempre conectada con la dialéctica socioespacial. Por tanto, se trata de dar mayor importancia a cómo lo espacial configura y fija lo social en diferentes dimensiones, tanto en la inmediatez de las relaciones personales como en las de grupo, de clase, en la estratificación de la sociedad o en lucha de poderes. Así pues, no primaríamos, de dicha dialéctica, cómo lo social construye lo espacial (que es a lo que tradicionalmente se ha dado más énfasis). No obstante tal opción, lo social también es importante, dado que, desde nuestro punto de vista, la ciudad está imbricada con lo discursivo y con la construcción social; es decir, a partir de nuestras prácticas y discursos sobre la urbe estamos provocando ciertos significados sobre el espacio, a la vez que damos forma a los objetos que lo componen (Foucault, 1984). Esta visión práctica y discursiva de la ciudad también ha sido mantenida por otros autores, como Di Masso (2007), que exploró la utilización discursiva del espacio público como un recurso retórico para la acción social localizada; o D’Aubeterre (2003), que abordó el estudio de la cotidianeidad urbana a través de las producciones discursivas.

En tercer lugar, al analizar los datos recogidos, estos nos pedían atender también a la composición del espacio de una forma virtual y a los imaginarios globales para dar cuenta de los fragmentos de realidad social estudiados. En este sentido, por tanto, nos vimos inmersos en un proceso de problematización (Gupta \& Ferguson, 1997) del lugar donde llevamos a cabo el trabajo de campo y un proceso de deslocalizar y multisituar (Marcus, 1995) nuestra etnografía urbana en un contexto sociohistórico caracterizado por múltiples conexiones e interacciones, donde lo global es inseparable de lo local y de lo cotidiano, y donde se articulan y establecen interconexiones en lugares, escalas y contextos diferentes. De esta forma, además de analizar la materialidad, la performatividad, las prácticas sociales y discursos que emergen, consideramos necesario incluir las cuestiones tecnológica y global, que también ensamblan el lugar que analizamos.

Estas tres tensiones y retos metodológicos se ven atravesadas por una negociación clara entre lo local y lo global. Considerar la globalización como un proceso 
histórico transcultural tiene la ventaja de proporcionar un marco predictivo para relacionarnos con los objetos/sujetos de estudio; pero, a la vez, genera una explicación fija, homogénea y un tanto limitada de la realidad social. Es decir, si nos limitamos a seguir las posibilidades que genera la globalización en cuanto a circulación y movimiento de personas, ideas, símbolos, capitales o instituciones, nuestra mirada etnográfica no daría cuenta de cómo este movimiento se produce porque existen diversas condiciones (agencias, condiciones sociales o razones políticas) que las permiten en un contexto local. Por ello, abogamos por una concepción de la globalización en plural, es decir, de "proyectos particulares de globalización" (Tsing, 2000, p. 347), en los que las especificidades culturales, regionales y locales hacen emerger diferentes ideas, agencias, prácticas y/o sujetos en tiempos y lugares específicos. En una línea similar, Appadurai (2013) pone de relieve la complejidad de los flujos culturales y los efectos que se producen en la "producción de lo local y en la producción de la subjetividad local” (pp. 62-63). En este sentido, se problematiza la polaridad local-global, incidiendo en que lo global no es un mero lugar accidental en el que se funde y confunde la circulación de elementos globales. Más bien, ese lugar deviene a través de una transformación mutua de formas que circulan y que producen localidades mediante la negociación y las tensiones mutuas entre ellas: la circulación de elementos globales creará situaciones de complejidad que dan forma a los contenidos de la práctica local. Así, los agentes, las instituciones, los actores y los poderes son los que producen las geografías, y no al revés (Appadurai, 2013); es decir, que no son un marco apriorístico, sino que están histórica y socialmente producidos. Por tanto, veremos cómo el evento que estamos analizando, producido en un espacio concreto de la ciudad, genera diferencias sociales a través de "geometrías de poder" (Massey, 2012, p. 116) que sitúan a los diferentes grupos sociales e individuos de maneras diferenciadas en los flujos e interconexiones.

De esta forma, para el análisis de los datos recopilados, decidimos clasificarlos en cuatro ejes diferenciados que proporcionan una sensibilidad etnográfica detallada: (i) materialidad; (ii) performatividad y prácticas sociales; (iii) narrativas y discursos; y (iv) virtualidad. Esta diferenciación no está exenta de dificultades, porque para abordar el objeto de estudio analizado es preciso capturar la interrelación entre los elementos tanto estructurales (acciones urbanísticas) como materiales (objetos y productos vintage nómadas); entre las prácticas de ocio y consumo donde cuerpos y estilos performan y transmutan el espacio; o entre las narrativas, discursos y virtualidades que reconfiguran y reconstruyen la realidad social a través de este tipo de eventos, dotando al espacio de una agencia propia. Por tanto, el "lugar-ensamblaje", como unidad de análisis, nos permite, por una parte, captar esas porciones de realidad múltiple en la que se ensamblan los cuatro ejes propuestos, y que pasamos a describir a continuación; y por otra, nos posibilita detectar las tensiones que en dicho espacio convergen entre los imaginarios y las narrativas globales, e identificar a los agentes, instituciones, individuos y posibilidades de producción local que en él se dan. 


\section{Análisis: ensamblando espacios creativos y culturales}

Inspirado en mercadillos europeos, La Placica Vintage representa una actividad local en la que el ocio y el consumo creativo se conciben como una cuestión conjunta, que emerge a partir de la transformación urbanística llevada a cabo a través del PERI. El evento es organizado y promocionado por los jóvenes emprendedores creativos que tienen sus locales en la parte baja del edificio, al que se suman los gestores de los equipamientos públicos y las instituciones municipales. Además de la apertura de estos locales comerciales, el patio interior se dispone para la ubicación de puestos relacionados con la recuperación de productos de segunda mano o vintage. Se construye así una atmósfera "retro" que se encarga de producir artículos y actividades como muebles restaurados; cámaras de foto "polaroid"; vinilos; bicicletas antiguas y fixies; exposiciones; cortes de barba; ropa de segunda mano; artículos para coleccionistas y antigüedades; talleres en los locales ubicados en el espacio; complementos; máquinas de escribir antiguas; juguetes de coleccionista, o aparatos electrónicos. Este evento se ha repetido ya en catorce ediciones y supone un uso, una práctica y una apropiación colectiva del espacio significativamente diferentes a los que acontecen cotidianamente (especialmente entre semana) en esta zona concreta de la ciudad.

\section{Materialidad}

Cualquier contexto material moldea y da forma a las narrativas y discursos sobre la naturaleza de los espacios y resignifica las actividades y prácticas que van a tener lugar en los mismos. La Placica Vintage se enmarca en un paisaje urbano renovado, regenerado y revitalizado, además de ser un evento que, de una forma puntual y efímera, despliega toda una serie de signos, símbolos, prácticas o estilos urbanos a través de la disposición de distintos puestos y el vaivén de curiosos y curiosas en busca de productos únicos.

Por un lado, y a nivel estructural, fruto del Plan Especial de Reforma Interior (PERI), y como hemos comentado con anterioridad, estas actuaciones han reconfigurado las posibilidades socioterritoriales y sociomateriales del espacio. Así, el nuevo paisaje urbano está conformado por el centro musical y un bar, que pretenden actuar de lugar de centralidad; una plaza pública; la edificación con nuevas viviendas en alquiler y los bajos en los que se albergan los locales de jóvenes emprendedores y creativos; además de una fuerte renovación del mobiliario urbano.

En este marco estructural y material es donde tiene lugar el evento de La Placica Vintage. La materialidad que se despliega durante esta actuación efímera dota al espacio de una agencia propia. El espacio que se representa a través de los objetos (con sus narrativas y simbología) no sería el mismo si en los diferentes puestos encontrásemos otros artículos (figuras $2 \mathrm{a}$ y $2 \mathrm{~b}$ ). Las paradas, las mesas, libros, tocadiscos, muebles, ropa, bisutería, bicicletas, encuadernaciones, vinilos, antigüedades, etcétera, convierten el espacio urbano en una tienda vintage al aire libre en la que se permite, todavía más, la libre circulación de mercancías y de personas, facilitando la adquisición y revalorización de productos que estaban en desuso. El discurso recopilado sobre este tipo de instalación queda legitimado cuando se relaciona con 
la cuestión del diseño, del arte, de la innovación y con la cuestión cultural. Además, se explicita que La Placica Vintage atrae a ciertos colectivos y personas de la ciudad que habitualmente no usan o practican esta zona degradada de Zaragoza.

EX 16: Somos una tienda de libros especializados en arte... también encontraremos algunos objetos realizados por diseñadores... [hacemos] talleres dedicados a incentivar la creatividad de los más pequeños. Tenemos exposiciones. Y en días como hoy, estamos animados y con iniciativas de este tipo se va atrayendo cada vez más a la gente a este barrio.

FIGURAS 2A Y 2B | Locales creativos y artículos puestos en venta
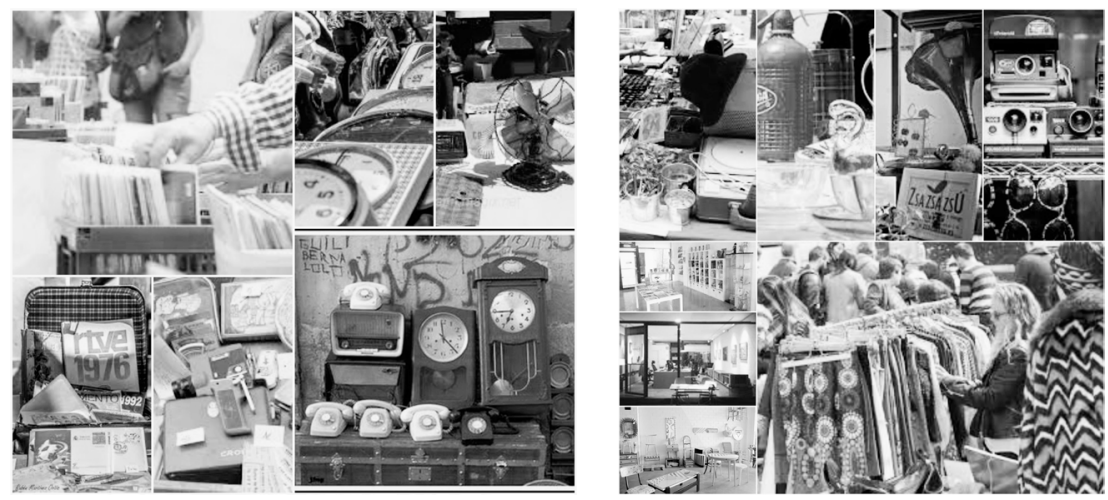

FUENTE ELABORACIÓN PROPIA A TRAVÉS DE IMÁGENES TOMADAS DE DIFERENTES WEBS Y BLOGS ACCESIBLES PÚBLICAMENTE

Conviven entonces dualidades materiales. Por un lado, un paisaje estructural urbano que confiere al espacio aire de revitalización y regeneración urbana, llevado a cabo en los últimos años a través de intervenciones públicas de promoción urbanística. Por otro, una transmutación espacial efímera y puntual a través del evento mercadillo vintage que recrea una atmósfera europea y globalizada, a la vez que moderniza y privatiza el espacio y acentúa la desigualdad ambiental de las zonas que aún no han sido transformadas.

La propia acción del mercado vintage, como decíamos, es de duración efímera. Responde así a "una materialidad urbana y a un proceso de construcción social en el cual el patrón de aglomeración colectivo es más nómada/líquido que fijo/ sólido" (Sabaté \& Tironi, 2008, p. 29). Esta forma de ciudad se relaciona directamente con un tipo de arquitectura característica: con estructuras intercambiables e incluso desechables, flexibles y maleables; con formas incompletas, abiertas y no jerarquizadas, donde se acaba difuminando el interior y el exterior de los lugares. Se constituye un tipo de lugar que se encuentra en un estado escurridizo y maleable; es decir -y como es el caso-, que se adapta al recipiente que lo contiene. En concreto, el mercado vintage se adapta al espacio en el que se lleva a cabo la intervención urbanística (PERI). 
Finalmente, podemos establecer un cierto paralelismo entre cómo se revalorizan los edificios y las zonas comerciales de las ciudades cuando se producen intervenciones urbanísticas y sociales, iniciándose ciertos procesos de gentrificación, y cómo, a través de ciertas actuaciones -en nuestro caso, La Placica Vintage-, los objetos antiguos que se venden, y el mercadillo en sí mismo, también se revalorizan. Al subir de valor, tanto los productos como esta tienda colectiva al aire libre se hacen accesibles solo para un determinado tipo de personas, con un cierto nivel adquisitivo y con un cierto interés hacia unos productos muy concretos. Así pues, la exclusión social de ciertos colectivos y personas del barrio se pone de manifiesto en las calles y en las plazas donde se instala el mercadillo vintage.

\section{Performatividad a través de las prácticas sociales}

Pasear, transitar, moverse, observar, mirar a través de los distintos puestos y rincones, así como comprar, obtener, fotografiar, compartir, comentar o actualizar un estado de las redes sociales potencian y facilitan otras formas y experiencias de lo comercial al amparo de discursos legitimadores sobre lo innovador, lo cultural y lo creativo.

Las personas que acuden a La Placica Vintage no son las habituales de este lugar (vecinos de fin de semana). La confluencia de personas de otros lugares de la ciudad a este espacio de centralidad performa y transmuta esta zona del barrio a través de sus prácticas, sus cuerpos, sus ropas, sus estilos, sus interacciones y transacciones y sus discursos. El mercadillo de lo antiguo y lo retro se concibe como un hecho excepcional y deviene una realidad sobrepuesta sobre la realidad urbana normalizada y cotidiana del barrio.

Amantes y coleccionistas de lo antiguo, curiosos, ciudadanos con un nuevo plan para las mańanas festivas, actores creativos, emprendedores e instituciones se dan cita y simulan, mediante narrativas y discursos concretos, una atmósfera del pasado y el presente y que se produce en un espacio local, pero que se conecta y desconecta continuamente de una escala global. Esta amalgama de fragmentos y nuevas realidades genera un imaginario retro que se actualiza en el contexto urbano actual a través de los objetos dispuestos en el espacio público, las personas que lo componen y el resto de elementos materiales que hemos descrito en el apartado anterior. Se produce, por tanto, una revalorización poscapitalista cool y snob de dichos objetos, lo que no deja de ser una paradoja del mismo sistema económico: los objetos envejecidos que están en desuso solo pueden ser adquiridos por determinados individuos.

EX 10: "Un oasis en el desierto", sonríe J. mientras apura la cerveza. Quien así habla es un padre de mediana edad que acude junto a su mujer y su hijo. La plaza Mariano de Cavia está llena de gente de todo tipo que busca todo tipo de cosas: ropa, decoración, comida... Un espacio abierto, en el sentido más amplio de la palabra, y que se ha convertido en un referente de la vida cultural en Zaragoza.

Las barreras, por tanto, entre el ocio y el consumo se diluyen. El consumo de este tipo de productos ya no tiene la única finalidad del intercambio económico de bienes por capital. El consumo se convierte en elemento dinamizador del espacio. La búsqueda de artículos exclusivos, de "gangas" y objetos retro, articula la vida 
efímera del espacio. El entorno, además de por los artículos, es performado a través de las tendencias que podemos ver en la ropa de los asistentes (figura 3, la variedad musical que encontramos con actuaciones de grupos en directo y djs que amenizan el espacio mediante los estilos más variados y determinados ( $p \circ p$, rock, funky, swing, boggie, garage, etcétera) y mediante actuaciones en directo de grupos de lindy-hop.

EX 11: Pasear entre los puestos es una aventura sensorial. La música brota de todos los rincones para acoger al visitante y no soltarlo nunca: "Antes no pisaba el barrio y ahora casi no puedo salir de aquí. Las Armas es como ese barrio especial que siempre veíamos en otras ciudades", explica A, estudiante de enfermería. Sus amigas vienen y se la llevan antes de que se pierda entre la gran cantidad de gente que acude.

FIGURA 3 | Asistentes al evento

figura 4 | Carteles La Placica Vintage, que evocan esa atmósfera retro

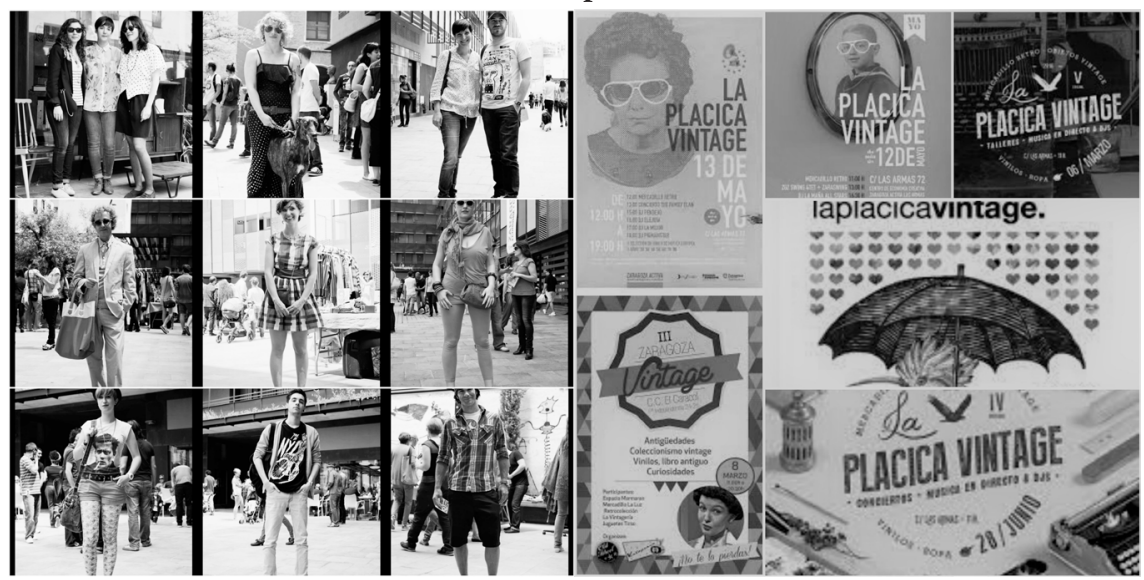

FUENTE ELABORACIÓN PROPIA A TRAVÉS DE IMÁGENES TOMADAS DE DIFERENTES WEBS Y BLOGS ACCESIBLES PÚBLICAMENTE

El espacio se reconfigura a través de las prácticas de un ocio y un consumo determinados. En él se entremezclan la revalorización de los objetos y la afluencia de agentes y personas con un determinado capital económico, social y cultural. Esto se puede relacionar con procesos de exclusión social: las actividades y prácticas asociadas al consumo y al ocio están definidas y orientadas principalmente en términos de grupos sociales que responden a un determinado "habitus" (Bourdieu, 1980). El "habitus", entendido como el proceso a través del cual se reproduce la cultura, valores y una normatividad social determinada, configura las relaciones de poder a través de los cuerpos (figura 3). Es en este sentido que afirmamos que el espacio genera un capital simbólico a través de las interacciones, que produce procesos de desplazamiento y segregación durante la duración de los eventos, y que se relaciona con una serie de narrativas y discursos como la revitalización, la modernización y la reapropiación del espacio. 


\section{Narrativas y discursos: revitalización y globalización bohemia}

La Placica Vintage se empieza a construir desde su propio nombre, que al mismo tiempo se constituye en el sobrenombre del evento. Diminutivo de plaza, los aragoneses usan en su lenguaje habitual este recurso lingüístico en algunas palabras: La Placica Vintage provoca un efecto de significado concreto para que las personas se fijen y se identifiquen todavía más en el evento y en el entorno en el que se lleva a cabo la actividad. Una identificación impensable para muchas de estas personas unos años atrás, teniendo en cuenta los imaginarios colectivos sobre el barrio relacionados con su olvido durante ańos, en particular la conflictividad en la convivencia, su peligrosidad y las prácticas ilícitas. ${ }^{4} \mathrm{El}$ diseño de los carteles del evento ha variado en cada edición, pero aquello que no queda alterado por el paso del tiempo es el nombre que se le otorga al acontecimiento. La combinación de plaza y vintage es elegida para resignificar la transformación de la cotidianeidad urbana en algo antiguo, bohemio y cool, pero otorgándole al mismo tiempo un valor: el concepto de plaza (pública) se transmuta hacia lo económico y lo comercial. La Placica Vintage emerge como evento obligado y actúa como elemento que conecta realidades, diseńos, materialidades, materiales, objetos, música, creaciones, atmósferas, etcétera. Tal y como apunta Sack (1986), las palabras, de forma simultánea, ya marcan los límites a la vez que se escriben o se leen, declaran sobre la dirección de lo que tiene que ser un espacio en relación con la posesión y la exclusión, con lo que se tiene que ejecutar, como práctica social y como naturaleza, respecto de un lugar.

Durante este evento se reproducen narrativas sobre La Placica Vintage que legitiman la actividad como un fin para la revitalización del espacio en particular y del barrio en general. De la misma forma, se compone un imaginario discursivonarrativo local en el que la revitalización del espacio a través de este tipo de eventos es positiva per se. Es, además, una revitalización que tiene que compararse e imitar a un imaginario global de barrio europeo.

EX 2: Nos interesa que la gente de Zaragoza conozca esta parte de la ciudad, que es muy desconocida para la mayoría. Y nos interesa darle oportunidad a los emprendedores, a los emprendedores creativos, que definimos un poco los artistas, artesanos, la gente que está diseñando moda, fotografía, etcétera, y generar así un poco de identidad cultural, de idiosincrasia, dándole un aroma de barrio europeo.

EX 4: Muy bien, me parece estupendo... Es una iniciativa muy importante para el barrio -que estaba un poco deprimido-, pues este tipo de cosas lo revitalizan en gran medida.

EX 13: En el epicentro del Barrio de San Pablo se encuentra la calle Las Armas (...) hasta convertirse en una calle apagada y con el triste honor de no tener ni un solo comercio que le diera vida. En este entorno se emprende el proyecto y se comienza

Para ampliar con algo más de detalle esta idea, véase Sánchez-Naudín (2015), en el que desde una aproximación discursiva al espacio objeto de estudio se utilizan los repertorios interpretativos como unidades de análisis del discurso para explorar las relaciones de los actores sociales con el espacio urbano. 
a regenerar una zona degradada de la ciudad desde la revitalización económica y cultural (...) un espacio de contagio de la creatividad ciudadana a través de los eventos (...) Regeneración urbana y reapropiación del espacio público.

Como se pone de manifiesto, por tanto, a través de los extractos que hemos incluido en otros apartados y en este mismo, el ocio y el consumo creativo son elementos articuladores de discursos más amplios que transitan y permean el espacio. Iniciativas de este tipo, que evocan imaginarios deslocalizados por diferentes partes de Europa y sus mercadillos de segunda mano característicos, responden a una suerte de voluntad y necesidad de modernización de las prácticas de ocio, a la vez que resitúan el espacio en una tensión temporal que lo categoriza en dos tiempos diferentes: el espacio a través de La Placica Vintage deviene moderno, cool y alternativo; el espacio sin este tipo de eventos se ancla en su cotidianeidad tradicional. Estos "usos opresivos del tiempo" (Fabian, 2002, p. 2), a la vez que levantan barreras entre los dos espacios, legitiman en cierta manera la revitalización y regeneración urbana que se ha llevado a cabo y el mantenimiento y reproducción de este tipo de eventos.

Adicionalmente, "reapropiarse del espacio público" es una narrativa que excluye por definición. La reapropiación conlleva volverse a apropiar de algo que un día fue "nuestro". Ese endogrupo se construye en contraposición a otros grupos sociales que quizá no sean tan deseables y que en un momento determinado "ocuparon" un espacio que se define como público, pero que en realidad solo es accesible a ciertas prácticas y grupos legitimados. Sostener este tipo de discursos y no otros, relacionados con la convivencia o con el hecho de compartir espacios, genera realidades sociales en las que los actores, las instituciones y las prácticas son cómplices de procesos de desplazamiento y segregación entre los grupos.

\section{Virtualidad}

Como decíamos anteriormente, al abordar nuestro espacio objeto de estudio vimos que se encuentra atravesado por transformaciones de usos y apropiaciones relativas a determinados días de la semana, y por narrativas que evocan imaginarios globales. Ello, a su vez, implicó que el trabajo de campo también debiera deslocalizarse y enfocarse en los espacios virtuales de los que el espacio material se compone. Así, la etnografía también se sitúa de una forma múltiple a través de distintos elementos sociotécnicos, como dispositivos móviles, redes sociales, agendas culturales locales en versión papel y web y blogs.

El espacio se compone antes, durante y después del evento a través de las posibilidades que ofrecen las interacciones virtuales y cara a cara, generando un buzz local (Storper \& Venables, 2004). Al decir que La Placica Vintage es un buzz, queremos poner de relieve una serie de narrativas e interacciones que se producen entre las personas, y que hacen que se genere una atmósfera sobre el espacio que lo convierte en una cita obligada. Esto es, de este evento se habla por todos los rincones de la ciudad.

EX 9: Como decía... Contagiar, contagia. Cada vez que arrastro a alguien a este tipo de mercadillos, repite sin necesidad de ser arrastrado, incluso aunque no sufra de mi patología consumista. ¡Y repetirán el 3 de julio! Es verano, que alguien me explique cuál es el plan que puede competir contra una Placica y su ambientazo de 
vermuteo, con objetos de todo tipo y música, para los grandes y los más peques. Qué importa si te llama más la ropa -justificado a más no poder con los puestos de ropa que he visto en cada edición, os lo dice alguien que ha pasado más horas en tiendas de segunda mano que durmiendo- o si buscas ese disco que necesitas para respirar. Consumistas, musicófagos, gente de relax y gente del vino de los domingos, madres y padres que quieren ver bailar a sus peques, amantes de la moda y de todo lo retro y vintage... ¡La Placica es EL lugar!

Además de las interacciones cara a cara, los flyers que se producen para promocionar el evento (figura 4) y las agendas culturales en formato digital o en papel tienen la capacidad de deslocalizar el espacio y dotarlo de ubicuidad.

\section{FIgURA 5 | Comunicación virtual del evento}

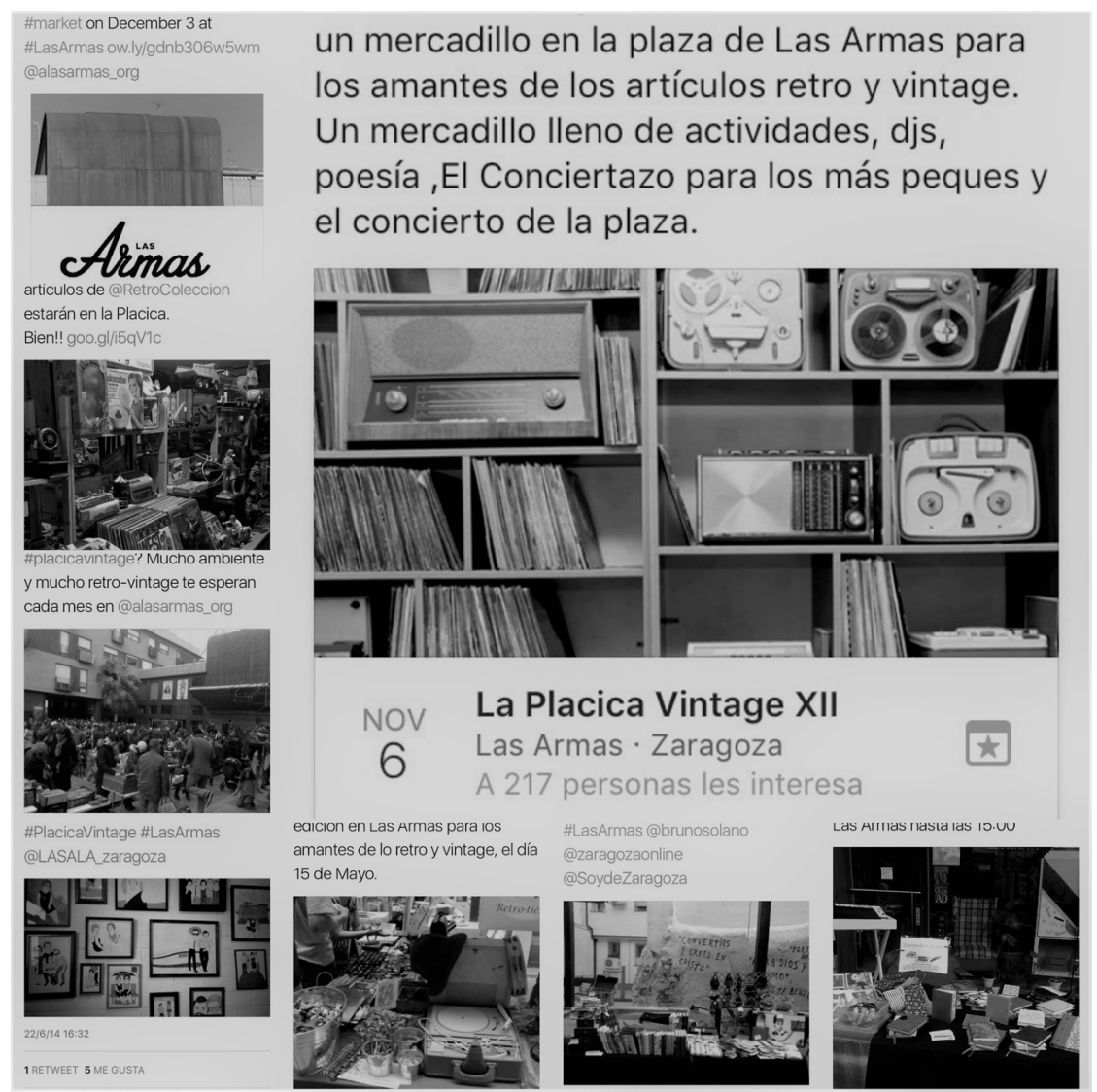

FUENTE ELABORACIÓN PROPIA A TRAVÉS DE IMÁGENES TOMADAS DE DIFERENTES WEBS Y BLOGS ACCESIBLES PÚBLICAMENTE

El evento se deslocaliza y se va componiendo también a través de la información transmitida por medio de las instituciones organizadoras del evento, los propios "creativos" que tienen un puesto en el mercadillo vintage o, de una manera 
espontánea, personas que tienen pensado ir al espacio. Las redes sociales emergen no solo como un dispositivo que recoge y comparte informaciones y como un panóptico relacional, sino también como un terreno en el cual se performan y representan las prácticas que se llevan a cabo respondiendo a una necesidad de compartir el "estar allî".

Así, por ejemplo (figura 5), se pueden ver estados de Facebook haciendo mención al evento que tendrá lugar en unos días o información en blogs sobre el mismo; o recibir una invitación al evento a través de esta red social e interesarse por las personas que pretenden asistir o interaccionar con ellas. Se puede seguir lo que está pasando o compartir si se está ahí a través de la etiqueta \#LaPlacicaVintage en Twitter o Instagram, de la misma forma que, pasados los días, pueden encontrarse menciones al mismo.

La información que se emite sobre La Placica Vintage va dirigida a un público muy específico, a un sector de personas que están dentro de unos circuitos culturales y sociales concretos. Podemos vislumbrar, en este sentido, que aparecen ciertas diferencias y desigualdades en relación con los grupos sociales que, finalmente, acceden y reproducen la información relacionada con el mercadillo vintage.

Finalmente, el evento y -por ende- el espacio, se descomponen en tiempos diferentes que los configuran y actualizan constantemente en su significación. Por un lado, las informaciones acerca de su próxima realización, sus novedades, los diferentes propietarios de los puestos que anuncian su presencia, las interacciones virtuales entre las personas que pretenden acudir o las actuaciones que van a tener lugar, entre otros. Por otro, ese "estar alli" traspasa las barreras físicas y materiales y hace que el espacio transite, se deslocalice y esté presente a la vez en otros lugares. En definitiva, si bien el espacio a través del evento tiene una duración efímera y caduca, las posibilidades de virtualidad y ubicuidad hacen emerger un espacio en un presente continuo.

\section{Conclusiones}

El espacio del mercadillo vintage, espacio poscapitalista y cosmopolita, emerge en esta parte de la ciudad mediante la apropiación, usos, prácticas, resignificaciones, narrativas y objetos materiales que lo componen. Es un espacio que se transforma a través de la interrelación de arquitecturas efímeras, de actores (humanos y no humanos), de narrativas, de representaciones/performaciones y de ciertas prácticas sociales y económicas concretas que, en conjunto, se articulan y ensamblan este espacio. De esta forma, La Placica Vintage produce una reconfiguración socioterritorial y sociomaterial del espacio. Hemos puesto de manifiesto cómo los elementos materiales (objetos que se ponen en venta, la arquitectura de las viviendas, el centro musical o la localización de los locales de emprendedores creativos, entre otros) dotaban al espacio de agencia a través de una narrativa y una simbología propias del imaginario creativo y cultural.

Este paisaje urbano material moderno, cool y bohemio, genera una atmósfera que congrega a vecinos de fin de semana atraídos por las posibilidades de ocio y de consumo que se ponen a su disposición. Es un espacio que se actualiza de manera 
constante y ubicua; que está presente, a través de dispositivos sociotécnicos, más allá de los días en los que se lleva a cabo. Los objetos que se adquieren, el ocio consumista o la música que se escucha son ejemplos de un capital económico, social y cultural que, a la vez que seduce a personas de otras partes de la ciudad a través de las narrativas en torno a la globalización bohemia, segrega, excluye y desplaza a vecinas y vecinos cuya cotidianeidad urbana se ve alterada, provocando en ocasiones procesos de conflictividad vecinal. El espacio que se compone, además, produce una tensión entre categorías como moderno-degradado que legitiman este tipo de intervenciones de revitalización y regeneración urbana.

Las posibilidades que nos ofrece el "ensamblaje-lugar" permiten que nos acerquemos a un espacio como el que hemos analizado, en el que se articulan procesos de segregación, exclusión y desigualdad en los que subyacen ideologías del capitalismo tardío, y en los que se insertan discursos en torno a la globalización cultural y creativa que tensionan la cotidianeidad urbana. El espacio como nexo discursivo/ material y como ensamblaje dinámico hace emerger una serie de elementos localizados y deslocalizados, en diálogo continuo entre lo local y lo global. Estos nos alertan a priori de posibles procesos de gentrificación a través de la composición de espacios efímeros y adulterados en los que las actividades de ocio y consumo cultural y creativo se alinean con los procesos de regeneración urbana.

El círculo esta vez no se ha cerrado. Una vez que se ha producido la revalorización del espacio y el desplazamiento de los residentes tradicionales, fruto de la llegada de otras personas con rentas más altas, los estudios sobre gentrificación suelen poner el acento en distintas variables: las transformaciones urbanísticas relacionadas con la dimensión arquitectónica o física; los procesos de regeneración urbana y su relación con los usos recreativos y comerciales, y con los cambios en la ocupación social del espacio; o las oportunidades de consumo, estilo de vida o emprendimiento creativo. Ahora bien, lo que se propone en este artículo es poner de relieve que la producción de este tipo de actuaciones e intervenciones efímeras y puntuales hace emerger una serie de dinámicas sociales y económicas que, junto a otras intervenciones urbanas, generan procesos de exclusión y segregación social, y que apuntan hacia dinámicas de gentrificación de espacios céntricos de ciudades que históricamente son olvidados y degradados.

\section{Referencias bibliográficas}

Anderson, A. (1985). Kreativitet. Storstadens framtid. Estocolmo: Prisma.

Appadurai, A. (2013). How histories make geographies: Circulation and context in a global perspective. En The future as a cultural fact: Essays on the global condition (pp. 61-69). Londres: Verso.

Boschma, R. A. \& M. Fritsch. (2009). Creative class and regional growth: Empirical evidence from seven European countries. Economic Geography, 85(4), 391-423. https://doi. org/10.1111/j.1944-8287.2009.01048.x

Bourdieu, P. (2007). El sentido práctico. Buenos Aires: Siglo xxi. 
Cassián, N. (2012). De qué está hecha una ciudad creativa. Una propuesta para abordar la cultura, el ocio y la creatividad en la urbe contemporánea. Athenea Digital, 12(1), 169190. http://www.redalyc.org/articulo.oa?id $=53723265010$

Castells, M. (1995). La ciudad informacional: tecnologias de la información, reestructuración económica y proceso urbano-regional. Madrid: Alianza Editorial.

Deutsche, R. \& Ryan, C. G. (1984). The fine art of gentrification. October, 31, 91-111. https:// doi.org/10.2307/778358

D’Aubeterre, L. (2003). Ciudad, discursividad, sentido común e ideología: un enfoque psicosocial de la cotidianidad urbana. Espacio Abierto, 12(2), 169-186. http://www. redalyc.org/articulo.oa?id=12212202

Di Masso, A. (2007). Usos retóricos del espacio público: la organización discursiva de un espacio en conflicto. Athenea Digital, 11(1), 1-22. https:/ddd.uab.cat/pub/athdig/1 5788946n11/15788946n11p1.pdf

Di Masso, A. \& Dixon, J. (2015). More than words: Place, discourse and the struggle over public space in Barcelona. Qualitative Research in Psychology, 12, 45-60. https://doi.or $\mathrm{g} / 10.1080 / 14780887.2014 .958387$

Fabian, J. (2002). Time and the emerging other. En J. Fabian. Time and the Other. How Anthropology makes its object (pp. 1-35). Nueva York: Columbia University Press.

Farías, I. (2011). Urban assemblages: How actor-network theory changes urban studies. Londres: Routledge.

Florida, R. (2002). The rise of the creative class: and how it's transforming work, leisure, community and everyday life. Nueva York: Basic Books.

Florida, R. (2009). Who's your city? How the creative economy is making where to live the most important decision of your life. Nueva York: Basic Books.

Foucault, M. (1984). Des espaces autres (conférence au Cercle d'études architecturales, 14 mars 1967). Dits et écrits II, 1976-1984. Architecture Mouvement Continuité, №5, octubre, 46-49. Gallimard. http://www.articule.net/wp-content/uploads/2008/11/ mfoucaultdesespacesautres.pdf

Fumagalli, A. (2010). Bioeconomía y capitalismo cognitivo. Hacia un nuevo paradigma de la acumulación. Madrid: Traficantes de Sueños.

Glass, R. (1964). London: Aspects of change. Londres: Centre for Urban Studies and MacGibbon and Kee.

Gupta, A. \& Ferguson, J. (1997). Discipline and practice: The field as site, method, and location in Anthropology. En A. Gupta \& J. Ferguson (eds.), Anthropological locations: Boundaries and grounds of a field science (pp. 1-46). Berkeley, CA: University of California.

Harvey, D. (1985). The urbanization of capital. Baltimore: The Johns Hopkins University Press.

Krätke, S. (2010). 'Creative Cities' and the rise of the dealer class: a critique of Richard Florida's approach to urban theory. International Journal of Urban and Regional Research, 34(4), 835-853. https://doi.org/10.1111/j.1468-2427.2010.00939.x

Jacobs, J. (1961). The death and life of great American cities. Nueva York: Random House.

Jacobs, J. (1969). The economy of cities. Londres: Johnatan Cape.

Landry, C. (2000). The creative city. A toolkit for urban innovation. Londres: Earthscan.

Landry, C. \& Bianchini, F. (1995). The creative city. Londres: Demos. 
Lang, R. E. \& Danielsen, K. A. (2005). Review roundtable: Cities and the creative class (by Richard Florida. Nueva York: Routledge. Journal of the American Planning Association, 71(2), 203-220 [Book Review]. https://doi.org/10.1080/01944360508976693

Ley, D. (1986). Alternative explanations for inner-city gentrification: a Canadian assessment. Annals of the Association of American Geographers, 76(4), 521-535. https://doi. org/10.1111/j.1467-8306.1986.tb00134.x

Ley, D. (1987). Reply: the rent-gap revisited. Annals of the Association of the American Geographers, 77(3), 465-468. https://doi.org/10.1111/j.1467-8306.1987.tb00172.x

Marcus, G. (1995). Ethnography in/of the world system: The emergence of multi-sited ethnography. Annual Review of Anthropology, 24, 95-117. https://doi.org/10.1146/ annurev.an.24.100195.000523

Marcuse, P. (1985). Gentrification, abandonment and displacement: connections, causes and policy responses in New York City. Journal of Urban and Contemporary Law, 28, 195240. https://openscholarship.wustl.edu/law_urbanlaw/vol28/iss $1 / 4$

Markusen, A (2006). Urban development and the politics of a creative class: evidence from a study of artists. Environment and Planning A, 38(10), 1921-1940. https://doi. org/10.1068/a38179

Massey, D. (2012). Un sentido global del lugar. En A. Albet \& N.Benach (eds.), Doreen Massey. Un sentido global del lugar (pp. 112-129). Barcelona: Icaria.

Melé, P. (2003). (Ré)investir les espaces centraux des villes mexicaines. En C. Bidou (dir.), Retours en ville - des processus de " gentrification " urbaine aux politiques de "revitalisation" des centres (pp. 175-2004). París: Descartes et Cie, collection Les urbanités.

Nichols, T. (2003). Urban amenities: Lakes, opera, and juice bars: do they drive development? En T. Nichols Clark (ed.), The city as an entertainment machine (pp.103-140). Research in Urban Policy, Vol. 9. Nueva York: Emerald Group Publishing Limited. Borrador en https://culturalpolicy.uchicago.edu/sites/culturalpolicy.uchicago.edu/files/clarkamenities.pdf

Peck, J. (2005). Struggling with the Creative Class. International Journal of Urban and Regional Research, 29(4), 740-770. https://doi.org/10.1111/j.1468-2427.2005.00620.x

Podmore, J. (1998). (Re)reading the "loft living" habitus in Montreal's inner city. International Journal of Urban and Regional Research, 22(2), 283-302. https://doi.org/10.1111/14682427.00140

Sabaté, J. \& Tironi, M. (2008). Rankings, creatividad y urbanismo. EURE, 34(102), 5-23. http://dx.doi.org/10.4067/S0250-71612008000200001

Sack, R. (1986). Human territoriality. Cambridge: Cambridge University Press.

Sánchez-Naudín, J. (2015). Repertorios interpretativos de un espacio en transformación: el caso de Armas-Casta Álvarez en Zaragoza. URBS. Revista de Estudios Urbanos y Ciencias Sociales, 5(1), 89-105. http://bit.ly/2BIzW7A

Scott, A. J. (2007). ¿Capitalismo y urbanización en una nueva clave? La dimensión cognitivocultural. Tabula Rasa, 6, 195-217. http://www.redalyc.org/pdf/396/39600609.pdf

Sequera, J. (2017). Ante una nueva civilidad urbana. Capitalismo cognitivo, habitus y gentrificación. Revista Internacional de Sociología (RIS), 75(1), 1-12. http://dx.doi. org/10.3989/ris.2017.75.1.15.31

Shaw, W. (2002). Culture, economics and evolution in gentrification. Just Policy, 28, 42-50. 
Shearmur, R. (2006). L'aristocratie mobile du savoir et son tapis rouge. Quelques réflexions sur les thèses de Richard Florida. En D. G. Tremblay \& R. Tremblay (dir.), La compétitivité urbaine à l'ére de la nouvelle économie. Enjeux et défis (pp. 285-303). Montréal: Presses Universitaires du Québec.

Slater, T. (2009). Missing Marcuse: On gentrification and displacement. City, 12(2-3), 292311. https://doi.org/10.1080/13604810902982250

Slater, D. \& Ariztía, T. (2009). Assembling Asturias: scaling devices and cultural leverage. En I. Farías y T. Bender (eds.), Urban assemblages: How actor-network theory changes urban studies (pp. 91-108). Londres: Routledge.

Smith, N. (1987). Gentrification and the rent-gap. Annals of the Association of American Geographers, 77(3), 462-465. https://lambethrenters.files.wordpress.com/2014/04/ smith-n-gentrification-and-the-rent-gap.pdf

Smith, N. (2002). New globalism, new urbanism. Gentrification as global urban strategy. Antipode, 34(3), 59-68. https://doi.org/10.1111/1467-8330.00249

Smith, N. \& Williams, P. (1986). Gentrification of the city. Boston: Allen \& Unwin.

Storper \& Venables, A. J. (2004). Buzz: face-to-face contact and the urban economy. Journal of Economic Geography, 4(4), 351-370. https://doi.org/10.1093/jnlecg/lbh027

Tsing, A. (2000). The global situation. Cultural Anthropology, 15(3), 327-360. https://doi. org/10.1525/can.2000.15.3.327

Unctad - United Nations Conference on Trade and Development (2008). Creative Economy Report 2008. Génova / Nueva York: Unctad/Division of International Trade and Commodities (DITC). http://unctad.org/es/Docs/ditc20082cer_en.pdf

Unctad - United Nations Conference on Trade and Development (2010). Creative Economy Report 2010. Génova / Nueva York: Unctad/Division of International Trade and Commodities (DITC). http://unctad.org/es/Docs/ditctab20103_en.pdf

Urry, J. (1990). The tourist gaze. Leisure and travel in contemporary societies. Londres: Sage.

Urry, J. (2008). La globalización de la mirada del turista. Barcelona Metròpolis. Revista de información y pensamientos urbanos, 72, 48-57. http://bit.ly/2kflx7F

Zukin, S. (1989). Loft living: Culture and capital in urban change. Nuevo Brunswick: Rutgers University Press. 